\title{
A lógica do mercado e suas implicações nas políticas e processos de avaliação da Educação superior
}

\section{The market logic and its implications at the policies and processes of evaluation of the Higher Education}

\author{
Altair Alberto Fávero* \\ Evandro Consaltér* \\ Carina Tonieto**
}

\begin{abstract}
RESUMO
O presente texto é resultado de uma pesquisa qualitativa, exploratória e bibliográfica, que buscou construir uma resposta satisfatória para o seguinte problema: quais são as evidências que apontam para a supremacia da visão mercantilista neoliberal na elaboração dos indicadores de qualidade da Educação Superior? O texto está dividido em três partes: na primeira, aponta-se o discurso da centralidade da avaliação na Educação Superior; na segunda parte, aborda-se a mercantilização da Educação Superior e o discurso em favor do mercado como critério de avaliação; na terceira e última parte, discute-se as implicações formativas provenientes do modelo educacional do mercado. Conclui-se que a lógica mercantil neoliberal e o caráter mercadológico da educação se ocultam por trás de indicadores de qualidade e de chavões de excelência, impactando na elaboração e condução das políticas de avaliação da Educação Superior.
\end{abstract}

Palavras-chave: Educação Superior. Avaliação. Qualidade. Mercantilização.

* Universidade de Passo Fundo. Passo Fundo, Rio Grande do Sul, Brasil. E- mail: altairfavero@gmail.com - https://orcid.org/0000-0002-9187-7283 - E- mail: evandroconsalter@ gmail.com - https://orcid.org/0000-0001-8798-8960

** Instituto Federal de Educação Ciência e Tecnologia do Rio Grande do Sul. Ibirubá, Rio Grande do Sul, Brasil.E-mail: tonieto.carina@gmail.com - https://orcid.org/0000-0001-9066-9637 


\begin{abstract}
The present text is the result of a qualitative, exploratory and bibliographical research that sought to construct a satisfactory answer to the following problem: what are the evidences that point to the supremacy of the neoliberal mercantilist vision in the elaboration of quality indicators of higher education? The text is divided into three parts: in the first, the discourse of the centrality of evaluation in higher education; in the second part, the commercialization of higher education and the discourse in favor of the market as an evaluation criterion; in the third and final part, the formative implications of the educational model of the market are discussed. It is concluded that the neoliberal mercantile logic and the marketing character of education are concealed behind quality indicators and excellent clues, impacting on the elaboration and conduction of higher education evaluation policies.
\end{abstract}

Keywords: Higher Education. Evaluation. Quality. Mercantilization.

\title{
Considerações iniciais
}

As discussões sobre a avaliação têm ocupado lugar de destaque na agenda das políticas educacionais no cenário da expansão da Educação Superior, além de serem uma preocupação constante em todas as instâncias da sociedade. Tais discussões são oportunas e necessárias não só para avaliar a qualidade da formação dos profissionais, dos cursos e das instituições envolvidas, mas também para projetar o futuro da Educação Superior no Brasil. A avalição tem sido indicada como sendo o principal meio para atingir a qualidade da Educação Superior. Entretanto, ao analisar os distintos momentos pelos quais a avaliação desse nível tem passado, percebe-se que o processo de mercantilização acaba indicando os critérios de qualidade.

O presente estudo tem por objetivo analisar as concepções de qualidade na avaliação da Educação Superior e suas implicações formativas decorrentes de um modelo educacional fortemente influenciado pelos discursos do mercado. Seguindo as reflexões de Verhne e Freitas (2012), Bertolin (2009), Akkari (2011), Castells (2011), Nussbaum (2015), Batista (2016), Dardot e Laval (2016), acreditamos que a avaliação tem sido um instrumento de legitimação de poder dos governos, altamente subservientes ao discurso economicista da mercantilização da educação, e tem induzido os sistemas educacionais, principalmente no que diz respeito às reformas de educação influenciadas pelos indicativos do mercado. Conforme Castells (2001) essas reformas têm 
reestruturado a educação e os currículos na direção da mercantilização, no sentido de promover o atendimento das demandas do mercado e em função da competitividade e produtividade.

O estudo apresentado é resultado de uma pesquisa básica, qualitativa, exploratória e bibliográfica, que buscou construir uma resposta satisfatória para o seguinte problema: quais são as evidências que apontam para a supremacia da visão mercantilista neoliberal na elaboração dos indicadores de qualidade da Educação Superior? O texto está dividido em três partes, nas quais se procurou organizar as evidência coletadas: na primeira, aponta-se o discurso da centralidade da avaliação na Educação Superior como forma de controle das instituições e de seus processos de modo a garantir maior eficiência e eficácia das instituições (primeira evidência), aumentando a competitividade e, por consequência, a corrida pela qualidade; na segunda parte, aponta-se a adoção da lógica do mercado e seus preceitos de gestão e controle, como accountability, metas, resultados, flexibilidade e superioridade do privado em relação aos público, como sinônimo de excelência em detrimento de condições, como condições de trabalho dos docentes, pesquisa e extensão (segunda evidência); na terceira e última parte, aponta-se o aligeiramento e o descompromisso com a formação humana e impacto social das instituições, principalmente pelo uso de estratégias deturpadoras da educação a distância (terceira evidência). Conclui-se que as três evidências apontadas são resultado dos desdobramentos da lógica mercantil neoliberal na condução das políticas de avaliação e controle da expansão da Educação Superior brasileira e permitem afirmar que há a supremacia de tal visão na elaboração dos indicadores de qualidade da Educação Superior brasileira.

\section{A centralidade da avaliação na Educação Superior}

A investigação e o debate sobre a avaliação têm ocupado um espaço de centralidade nas pautas sobre a educação e na agenda das políticas educacionais, não só no âmbito governamental, mas também na forma como a sociedade interage com as instituições educativas. Os resultados das investigações e os desdobramentos dos debates sobre avaliação são importantes não só para pensar a reconfiguração dos cenários educativos, mas também para instituir reformas e inovações pedagógicas que influenciam os modelos institucionais e sistemas, a forma como são drenados os recursos e principalmente a indução de critérios para definir padrões que interferem na elevação da qualidade da oferta dos serviços educacionais. 
No que se refere à Educação Superior, a avaliação tem ocupado um lugar preponderante na condução e indução das políticas educacionais, principalmente num cenário em que se revela uma tendência histórica de expansão pela via majoritariamente privada. Conforme ressalta Batista (2016, p. 114), tal tendência "[...] aumentou a responsabilidade do Estado em desenvolver um sistema de avaliação, como uma das prioridades da política governamental, com vistas a orientar a expansão da oferta, a elaboração de políticas públicas e a análise das realidades institucionais". Com base no sistema de avaliação, o Estado teria condições de indicar as fragilidades e potencialidades para realizar diagnósticos, tomar decisões e instituir padrões de qualidade para o desenvolvimento da educação e a promoção da cidadania. Conforme bem ressalta Gómez (2011, p. 168), o Estado teria a responsabilidade de medir, avaliar e fomentar a qualidade da Educação Superior, pois esta teria um "alto e crescente valor e aporte social, econômico e cultural" na sociedade contemporânea.

Pensada nessa perspectiva, a avaliação, portanto, não deveria estar desassociada das fortes e profundas transformações que têm ocorrido na sociedade contemporânea, tendo em vista que a própria expansão poderia garantir sua qualidade se houvesse a supervisão avaliadora do Estado. Sobre isso, Verhine e Freitas (2012) ressaltam que a avaliação é um instrumento de legitimação de poder governamental e tem exercido importante função na estruturação dos sistemas educacionais. No entanto, o próprio Estado tem sido induzido por políticas decorrentes da globalização e pelos organismos internacionais que têm fixado suas metas tendo em vista fatores políticos, econômicos e sociais. Assim, grande parte das reformas que possibilitaram a reestruturação da educação e dos currículos têm seguido as demandas de mercado em função da competitividade e da produtividade daquilo que Castells (1999) chama de "economia do conhecimento". Assim, como bem ressalta Batista (2016, p.115), "observa-se a aproximação do modelo de oferta educacional ao funcionamento da economia com aplicação de conceitos originários do meio econômico, como eficiência, produtividade, relações de mercado, clientela e preferência dos consumidores". Neste novo cenário, o Estado deixa de ser o Estado provedor e passa a se tornar um Estado avaliador (CASTELLS, 1999), como forma de legitimar seu poder de forma descentralizada. Nota-se, portanto, o caráter centralizador da avaliação no cenário da expansão da Educação Superior.

A avaliação da Educação Superior foi indicada nos principais dispositivos legais na Constituição Federal de 1988, Lei de Diretrizes e Bases da Educação Nacional (LDB) Lei $\mathrm{n}^{\circ}$ 9.394, de 20 de dezembro de 1996 (BRASIL, 1996) e o Plano Nacional de Educação (PNE) Lei ${ }^{\circ} 10.172$, de 09 de janeiro de 2001 (BRASIL, 2001), como sendo um procedimento para fins de garantia da qualidade. Nota-se nos três dispositivos indicados uma forte ênfase no fato 
de que a centralidade da avaliação resultaria na qualidade. Mas que tipo de qualidade? Que concepção de qualidade é adotada pelo Estado como sendo objetivo ou finalidade dos processos avaliativos da Educação Superior brasileira? Alguns estudos (BATISTA, 2016; BERTOLIN, 2009; BURLAMAQUI, 2008) analisam a polissemia, complexidade, ambiguidade e mesmo relatividade do termo "qualidade". Não é possível inferir uma definição clara da concepção de qualidade que ocorre nos dispositivos legais, apesar de indicada como finalidade principal dos procedimentos e processos avaliativos. Para além do que é dito nos documentos oficiais, Batista (2016, p.127) ressalta que "corroborando a inferência de que avaliação tem se tornado mercantilizada, distanciando-se da avaliação formativa [...], constata-se que avaliação passou a ser centrada nos indicadores preliminares de qualidade" transformando-se em rankings para promoção das IES. Os indicadores de qualidade, desse modo, refletem a visão mercadológica, pautados majoritariamente pela quantificação e classificação. A partir de tal lógica, a mercantilização transformou-se em critério de avaliação da Educação Superior, o que pontuaremos a seguir.

\section{A mercantilização da Educação Superior e o discurso em favor do mercado como critério de avaliação}

A Educação Superior tem sido constantemente afetada por um discurso inflamado e pretencioso de que o privado é melhor do que o público. Basta acessarmos os sites de Instituições de Ensino Superior (IES) privadas para nos depararmos com frases de efeito como: "Aqui o seu esforço ganha força"; "Mais próximo para você ir mais longe"; "Educação de qualidade para você mudar de vida"; "Retorne aos estudos"; Destaque-se no mercado de trabalho!" O fato é que essas instituições estão aumentando consideravelmente sua participação no ensino superior brasileiro.

Entendemos que esse crescimento é pautado pelo que Tello (2013) chama de neoliberalismo pedagógico, um processo gerencial dos sistemas educacionais que, ao assumir modelos do mercado como critérios de avaliação, favorece a concorrência do setor privado com o público, o que acarreta no desenvolvimento de mecanismos de seleção e exclusão, novas formas de gerenciamento e elaboração de estruturas curriculares, e coloca em risco a qualidade da educação e dos processos formativos. Dessa forma, julgamos oportuna a análise de alguns aspectos que são atribuídos como critérios de qualidade em educação na realidade brasileira e que tentam atribuir chavões do mercado, como accountability (prestação de contas), metas e resultados como sinônimo de excelência. 
Conforme os dados do Censo da Educação Superior de 2018 (BRASIL, 2019), o Brasil possui 2.537 IES. Dessas, 299 são IES públicas e 2.238 são IES privadas, o que nos permite dizer que $88,2 \%$ das Instituições de Educação Superior no Brasil são da rede privada. Quanto às IES públicas, 42,8\% são estaduais (128), 36,8\% são federais (110) e 20,4\% são municipais (61). No âmbito público, a maioria dessas IES são universidades $(53,8 \%)$, ao passo que no âmbito privado predominam as faculdades $(86,2 \%)$. Os números revelam a supremacia de instituições privadas na oferta do ensino superior no país. Essas instituições detêm 75,4\% (6.373.274) no total de matrículas de graduação. A rede pública, por sua vez, registra 24,6\% (2.077.481).

O Grupo Kroton, uma das maiores organizações educacionais privadas do Brasil e do mundo, lidera o ranking de matrículas na rede privada (KOIKE, 2018). Com quase 1 milhão de alunos, detém um lucro líquido anual de cerca de R \$ 505,9 milhões. É o líder do mercado da educação no Brasil. Atualmente, já faz parte das 5 empresas que mais recebem verbas do Governo Federal, principalmente via o Fundo de Financiamento Estudantil (FIES). Como segue a lógica do mercado, o grupo adota rígidas medidas em relação à gestão de suas unidades. Entre essas medidas, catracas que ficam automaticamente bloqueadas para um estudante que atrasar o pagamento de suas mensalidades e, principalmente, redução de gastos com o corpo docente e a estrutura das salas de aula.

Como uma empresa visa o lucro, neste caso, o lucro é representado pelo número de matrículas, onde os estudantes passam a ser seu capital. O gráfico seguinte mostra os percentuais e a evolução das matrículas por categoria administrativa no cenário dos últimos 10 anos.

\section{GRÁFICO 01 - EVOLUÇÃO DE MATRÍCULAS EM INSTITUIÇÕES DE ENSINO} SUPERIOR NO BRASIL POR CATEGORIA ADMINISTRATIVA - 2008-2018

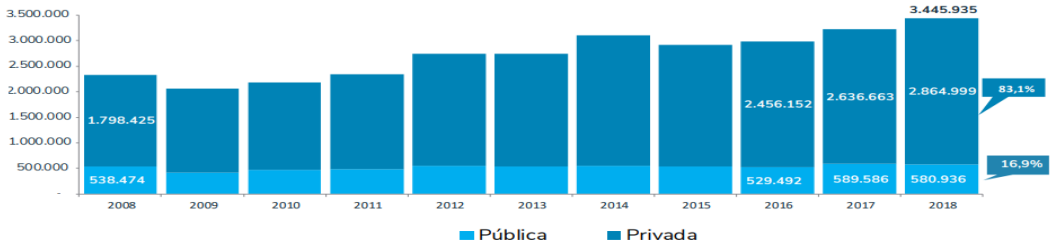

FONTE: Censo da Educação Superior (BRASIL, 2019). 
Este grande avanço do mercado educacional é fomentado, principalmente, pelo discurso de que a iniciativa privada é mais eficaz do que o setor público. Esse discurso apoia-se na justificativa de que o mercado é um mecanismo para a oferta da educação mais eficaz, ágil e eficiente. Além disso, seria possuidor de um conjunto de valores morais positivos por si mesmo, como o esforço, a austeridade, a autoconfiança e a independência. Ball (2001) afirma que essa perspectiva mostra o mercado como uma força transformadora que carrega e dissemina os seus próprios valores.

Diante deste novo ambiente moral, o estudante é cada vez mais mercantilizado. Conforme Ball (2001), cada estudante é posicionado/a e avaliado/a de uma forma diferente no mercado educacional, ou seja, o processo de competição institucional o apela para a "economia do valor do/a estudante". Dessa forma, entende-se que nos sistemas onde o recrutamento está diretamente relacionado ao financiamento e indicadores de desempenho, "os alunos são tomados como 'informações do mercado', considerando os 'custos' educacionais e a reputação do/a estudante" (BALL, 2001, p. 108).

Nesse contexto, os processos avaliativos na Educação Superior são tomados por muitas dessas instituições como estratégia de marketing. O Exame Nacional de Desempenho de Estudantes (ENADE), prova aplicada pelo Ministério da Educação (MEC) para os alunos de cursos de ensino superior, é um exemplo disso. O exame tem um grande impacto na Educação Superior brasileira, oferecendo algumas informações importantes a respeito das instituições. Conhecendo e avaliando o índice obtido pelo curso de uma instituição, seria possível, teoricamente, refletir sobre a qualidade da formação que ela oferece aos alunos. Na realidade não é bem isso que acontece.

Reportagem publicada na revista Veja (ALLEGRETTI, 2016), em outubro de 2016, revela possíveis fraudes que teriam sido praticadas por duas das maiores universidades privadas do Brasil, a Universidade Nove de Julho (UNINOVE) e a Universidade Paulista (UNIP). O objetivo era conseguir um bom resultado no ENADE. As manobras envolviam, basicamente, impedir a participação na prova de estudantes considerados "fracos", para evitar, assim, que prejudicassem a média final da instituição. Com uma boa nota, as instituições poderiam fazer propaganda de uma qualidade que, na realidade, não existiria.

Estes resultados "maquiados" reforçariam o discurso do mercado da eficiência e eficácia, como representante de processos educacionais inovadores, que aliados às mensalidades baixas, carga horária flexível e reduzida, aulas à distância e uma série de outros elementos cativadores, engordam a fatia de alunos e, consequentemente, a conta bancária dessas instituições. Além disso, conforme Bertolin (2009), apoiam-se na justificativa de que a competição de mercado induz à inovação e à adaptação dos sistemas às novas necessidades dos seus 
alunos e da sociedade, o que dificilmente seria possível em instituições públicas, principalmente em razão dos baixos investimentos que recebem do governo.

O que se observa, conforme afirma Bertolin (2009), não é bem assim. Essa qualidade, defendida a partir dos interesses do mercado, esbarra na defesa de reconhecidos investigadores, do princípio da Educação Superior como bem público, apresentando, entre outros argumentos, que o mercantil, bem ao contrário das características da universidade, possui interesses de curto prazo - lucro, retorno rápido - não conseguindo dar conta de problemas sociais que requerem tempo, investigação a longo prazo e profissionais que se dediquem integralmente às instituições.

O tempo dedicado pelos docentes para as instituições é um dos mais importantes indicadores de um processo avaliativo de verificação da qualidade. Docentes com dedicação exclusiva para a Educação Superior geralmente apresentam maior envolvimento com as questões acadêmicas, maior comprometimento com as instituições e, potencialmente, detêm maior titulação e envolvimento com projetos de investigação. Por outro lado, quanto menor a dedicação dos docentes para a Educação Superior, como é comum em instituições privadas - também aliada a uma alta rotatividade de docentes - menor a tendência de envolvimento com as questões fundamentais das IES e com suas dimensões acadêmicas e sociais (BERTOLIN, 2009).

Essa realidade fica estampada quando analisamos os dados divulgados pelo Censo da Educação Superior de 2018 (BRASIL, 2019). A tabela abaixo mostra o total de docentes em exercício no Brasil.

TABELA 01 - NÚMERO TOTAL DE DOCENTES EM EXERCÍCIO NO BRASIL POR CATEGORIA ADMINISTRATIVA DAS IES - 2008-2018

\begin{tabular}{|l|l|l|l|}
\hline \multirow{2}{*}{ ANO } & \multirow{2}{*}{ TOTAL } & \multicolumn{2}{|c|}{ DOCENTES EM EXERCICIO } \\
\cline { 3 - 4 } & & PÚBLICA & PRIVADA \\
\hline 2008 & 321.493 & 111.894 & 209.599 \\
\hline 2009 & 340.817 & 122.977 & 217.840 \\
\hline 2010 & 345.335 & 130.789 & 214.546 \\
\hline 2011 & 357.418 & 139.584 & 217.834 \\
\hline 2012 & 362.732 & 150.338 & 212.394 \\
\hline 2013 & 367.282 & 155.219 & 212.063 \\
\hline 2014 & 383.386 & 163.113 & 220.273 \\
\hline 2015 & 388.004 & 165.722 & 222.282 \\
\hline 2016 & 384.094 & 169.544 & 214.550 \\
\hline 2017 & 380.673 & 171.231 & 209.442 \\
\hline 2018 & 384.474 & 173.868 & 210.606 \\
\hline
\end{tabular}

FONTE: Censo da Educação Superior (BRASIL, 2019). 
No período analisado (2008-2018) é possível identificar um crescente aumento de docentes na rede pública, passando de $111.894 \mathrm{em} 2008$ para 173.868 em 2018. Por sua vez, a rede privada, que apresentou o maior crescimento no número de matrículas no mesmo periodo (196,6\%, conforme pode ser observado no Gráfico 05), teve um aumento muito inferior em relação ao número de docentes. Passou de 209.599 em 2008 para 210.606 em 2018. Esse pequeno aumento no número de docentes diante de um aumento tão exponencial no número de matrículas é reflexo de que o aumento de matrículas na rede privada se dá, principalmente, nos cursos na modalidade à distância, nos quais um mesmo professor atende a um número muito elevado de alunos dentro das plataformas de ensino.

Um fator importate de ser observado diz respeito ao regime de trabalho desses docentes.

GRÁFICO 02 - PARTICIPAÇÃO DE DOCENTES NA EDUCAÇÃO SUPERIOR, POR CATEGORIA ADMINISTRATIVA, SEGUNDO O REGIME DE TRABALHO BRASIL - 2008-2018 - REDE PÚBLICA

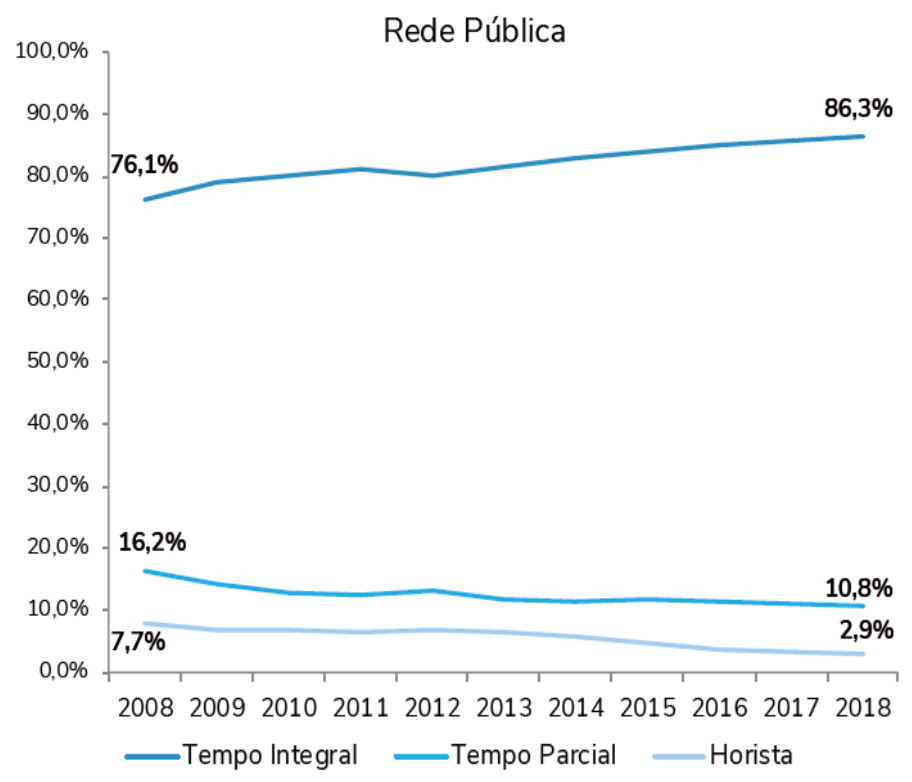

FONTE: Censo da Educação Superior (BRASIL, 2019).

Na rede pública, $86,3 \%$ dos docentes possuem regime de trabalho em tempo integral, enquanto $10,8 \%$ possuem regime em tempo parcial e apenas 
2,9\% são horistas. Quando analisado o período 2008-2018, pode ser observado um crescimento de docentes com regime de trabalho em tempo integral e uma redução de docentes em regime de trabalho em tempo parcial e horistas. Esses mesmos indicadores são muito diferentes quando observamos a realidade na rede privada (Gráfico 03).

GRÁFICO 03 - PARTICIPAÇÃO DE DOCENTES NA EDUCAÇÃO SUPERIOR, POR CATEGORIA ADMINISTRATIVA, SEGUNDO O REGIME DE TRABALHO BRASIL - 2008-2018 - REDE PRIVADA

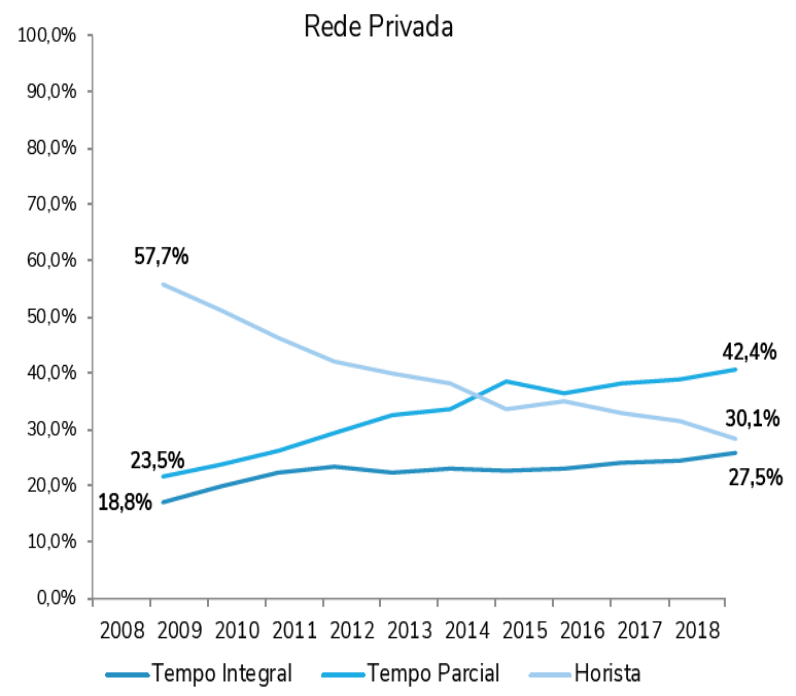

FONTE: Censo da Educação Superior (BRASIL, 2019).

Embora haja uma redução significativa de docentes em regime de trabalho horista no período 2018-2018, os indicadores apontam um aumento expressivo no número de professores em tempo parcial, passando de 23,5\% em 2008 para $42,4 \%$ em 2018. Juntos, esses dois regimes de trabalho representam $72,5 \%$ dos docentes que atuam na rede privada de ensino superior. Quanto ao número de docentes em tempo integral, observou-se um pequeno avanço, passando de $18,8 \%$ em 2008 para $27,5 \%$ em 2018. Esses dados, na maioria das vezes, estão ocultos à percepção dos discentes, porém impactam diretamente na qualidade dos cursos e das próprias IES, tendo em vista que professores com dedicação exclusiva ou regime de trabalho em tempo integral, geralmente, possuem uma maior identificação e dedicação com a instituição, com o curso em que atuam e com própria prática pedagógica e exercício profissional. 
Dentre outros aspectos que ficam ocultos ao merchandising das instituições privadas, como apontado pelo estudo de Bertolin (2009), estão os de que as instituições com tal perfil possuem as piores relações entre discentes e docentes com título de doutor e, principalmente, uma reduzida participação nas publicações científicas relevantes, o que revela seu distanciamento e pouco envolvimento com a relevância social da pesquisa e com a própria pesquisa.

Essa realidade pode ser observada quando analisamos o relatório divulgado pela Coordenação de Aperfeiçoamento de Pessoal de Nível Superior (Capes), produzido pela empresa americana Clarivate Analytics, ligada à multinacional Thomson Reuters, sobre a pesquisa científica no Brasil entre 2011 e 2016. Usando recursos bibliométricos, o relatório analisou o desempenho de trabalhos de pesquisa brasileiros publicados no período na Web of Science, cujo acesso aos brasileiros é permitido pelo Portal de Periódicos da CAPES. De acordo com o relatório, o Brasil produziu nesse período cerca de 250 mil papers. Entre as 20 instituições que mais produziram papers e que mais tiveram impacto estão 15 universidades federais e 5 universidades estaduais, conforme mostra o gráfico abaixo.

GRÁFICO 04-DESEMPENHO DAS PRINCIPAIS UNIVERSIDADES BRASILEIRAS EM PESQUISA NO PERÍODO 2011 - 2016

\begin{tabular}{|c|c|c|c|c|}
\hline Universidade & $\begin{array}{l}\text { Documentos na } \\
\text { Web of Science }\end{array}$ & $\begin{array}{c}\text { Impacto } \\
\text { da citaçäo }\end{array}$ & $\begin{array}{c}\text { Artigos no } \\
\text { Top } 1(\%)\end{array}$ & $\begin{array}{l}\text { Artigos no } \\
\text { Top } 10(\%)\end{array}$ \\
\hline Univ. de São Paulo (USP) & 54.108 & 0,93 & 1,06 & 7,96 \\
\hline Univ. Estadual Paulista & 20.023 & 0,79 & 0,69 & 6,10 \\
\hline Univ. Estadual de Campinas & 17.279 & 0,94 & 1,22 & 8,35 \\
\hline Univ. Federal do Rio de Janeiro & 16.203 & 0,93 & 1,11 & 8,18 \\
\hline Univ. Federal do Rio Grande do Sul & 14.611 & 0,89 & 0,86 & 6,6 \\
\hline Univ. Federal de Minas Gerais & 13.294 & 0,88 & 0,67 & 6,24 \\
\hline Univ. Federal de São Paulo & 10.667 & 0,93 & 1,05 & 6,15 \\
\hline Univ. Federal do Paraná & 8.233 & 067 & 0,44 & 5,31 \\
\hline Univ. Federal de Santa Catarina & 7.908 & 0,91 & 0,66 & 6,79 \\
\hline Univ. do Estado do Rio de Janeiro & 6.433 & 1,01 & 1,45 & 8,98 \\
\hline Univ. Federal de Pernambuco & 6.420 & 0,73 & 0,48 & 5,51 \\
\hline Univ. Federal de Viçosa & 6.373 & 0,63 & 0,56 & 4,33 \\
\hline Univ. de Brasilia & 6.218 & 0,89 & 1,13 & 6,10 \\
\hline Univ. Federal de Săo Carlos & 5.794 & 0,72 & 0,50 & 6,28 \\
\hline Univ. Federal de Santa Maria & 5.750 & 0,65 & 0,24 & 4,96 \\
\hline Univ. Federal do Ceará & 5.621 & 0,76 & 0,75 & 6,12 \\
\hline Univ. Federal Fluminense & 5.441 & 0,71 & 0,70 & 5,99 \\
\hline Univ. Federal de Golás & 4.217 & 0,74 & 0,81 & 5,90 \\
\hline Univ. Federal da Bahia & 4.198 & 0,81 & 0,88 & 6,77 \\
\hline Univ. Estadual de Maringa & 4.067 & 0,61 & 0,44 & 4,50 \\
\hline
\end{tabular}

FONTE: Clarivate Analytics Research in Brazil 2018. 
Os dados apurados pelo relatório mostram que praticamente não há produção científica significativa em instituições privadas no Brasil. A Universidade de São Paulo (USP), estadual, lidera a produção quantitativa e a Universidade do Estado do Rio de Janeiro (UERJ), também estadual, é a que possui produção de maior impacto. O fato de as IES privadas possuírem em seu quadro menos docentes em regime integral e com maior dedicação e envolvimento com projetos de pesquisa reflete os dados apurados pela Clarivate Analytics (CROSS; THOMSON; SIBCLAIR, 2018).

Para Bertolin (2009), essa realidade se justifica pela razão da própria natureza dos mercados e das IES privadas com fins lucrativos, as quais, logicamente, requerem lucros. Portanto, tais instituições necessitam cobrar mensalidades superiores aos seus custos e respondem prioritariamente às demandas dos indivíduos e organizações que as financiam, não às necessidades da sociedade como um todo. Desta forma, a pesquisa e a sua relevância social acabam sucumbindo à margem do processo educativo.

Utilizamos esses argumentos apresentados por Ball (2001) e Bertolin (2009) justamente para contrapor a recorrente e disseminada concepção de que o privado é melhor que o público, inclusive no campo da Educação Superior. É muito comum encontrarmos termos como "metas" "indicadores", "resultados", "eficácia" associados às ações publicitárias de instituições de caráter privado. Todavia, como a lógica deste setor é a lógica do lucro, elementos determinantes para a qualidade da Educação Superior, como as condições de trabalho dos docentes e o envolvimento com a pesquisa e a extensão, são deixados de lado em detrimento do retorno rápido e da inexistência de vínculos e compromissos com a comunidade em que estão inseridas. Tais escolhas, ou modus operandi, dessas instituições têm implicações para os processos formativos, conforme apontaremos a seguir.

\section{Implicações formativas provenientes do modelo educacional do mercado}

As implicações provenientes de modelos educacionais pautados pelo mercado vão além de números e indicadores que, supostamente, legitimariam a qualidade das instituições. Como analisamos na seção anterior, elementos fundamentais para a qualidade da educação como as condições de trabalho dos docentes e o envolvimento com pesquisa incidem diretamente sobre as características formativas dos discentes. 
Dessa forma, quando a Educação Superior é pautada pela lógica do mercado, esses aspectos ficam em segundo plano e abre-se espaço a emergência de modelos educacionais que concebem as instituições de ensino como uma empresa, onde os discentes assumem o papel de clientes. Para Bittencour (2014, p. 250), nesse cenário, "a relação pedagógica entre professor e aluno se converte em uma relação comercial, na qual o docente se encontra na obrigação de tal como um vendedor de conhecimento, a satisfazer todos os caprichos de seu cliente". Dessa forma, o próprio processo de ensino se flexibiliza e se torna cada vez menos exigente intelectualmente.

Um exemplo dessa flexibilização pode ser o exacerbado crescimento da Educação Superior à Distância $(\mathrm{EaD})$ no Brasil. Inicialmente, essa modalidade de ensino objetivava levar o acesso ao Ensino Superior até as regiões mais remotas do país, onde o deslocamento para os centros universitários era dificultado pela falta de infraestrutura de transportes. Agora, conquista alunos de todas as superfícies geográficas do país, inclusive de pessoas que moram ao lado de centros universitários presenciais. Conforme os dados do Censo da Educação Superior de 2018 (BRASIL, 2019), o aumento do número de ingressantes entre os anos de 2017 e 2018 é ocasionado, exclusivamente, pela modalidade à distância, a qual teve uma variação positiva de $27,9 \%$ entre esses anos, enquanto nos cursos presenciais houve uma variação negativa de $-3,7 \%$. Se considerado o período 2008-2018, os dados são ainda mais impressionantes; O número de ingressos variou positivamente $10,6 \%$ nos cursos de graduação presencial e triplicou (196,6\%) nos cursos à distância. Se em 2008 a participação percentual dos ingressantes em cursos de graduação à distância era de 19,8\%, em 2018 saltou para $40 \%$, atingindo a marca de mais de 1,3 milhões de matrículas (Gráfico 05). Essa modalidade de ensino, contudo, ainda desponta muitas dúvidas.

GRÁFICO 05 - EVOLUÇÃO DE MATRÍCULAS EM INSTITUIÇÕES DE ENSINO SUPERIOR NO BRASIL POR MODALIDADE DE ENSINO, NO PERÍODO 2008 $-2018$

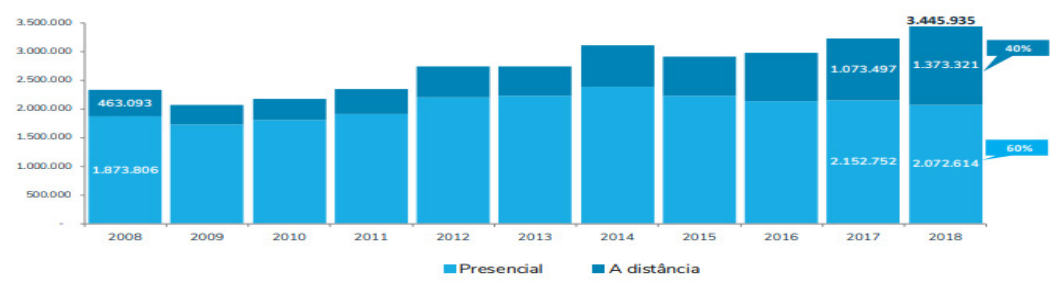

FONTE: Censo da Educação Superior (BRASIL, 2019). 
Outro dado importante de ser considerado é o de que a maioria dessas IES à distância é da rede privada. Os indicadores do Censo da Educação Superior (BRASIL, 2019) mostram que no ano de 2018 o Brasil possuía apenas $8,4 \%$ dos cursos de graduação à distância pertencentes à rede pública. Os outros $91,6 \%$ dos cursos estão alocados em instituições privadas, com finalidade lucrativa. $\mathrm{O}$ gráfico a seguir apresenta os números apurados.

GRÁFICO 06 - NÚMERO DE CURSOS DE GRADUAÇÃO À DISTÂNCIA NO BRASIL NA REDE PÚBLICA E NA REDE PRIVADA NO ANO DE 2018

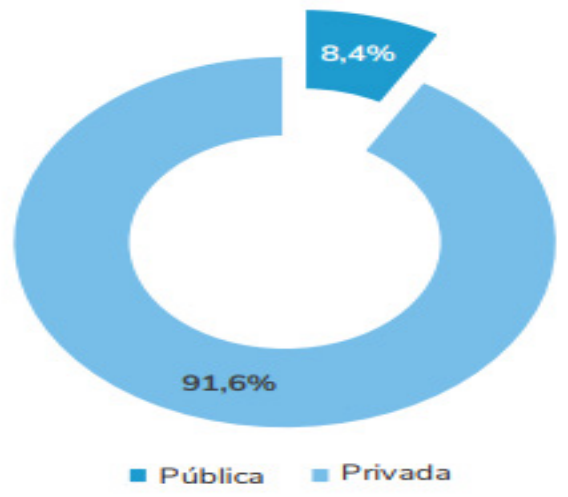

FONTE: Censo da Educação Superior (BRASIL, 2019).

Embora se saiba da existência de bons cursos de educação à distância, tanto na rede pública como na privada, também se observa o contrário. Por ter sua oferta concentrada principalmente em instituições particulares, das quais muitas compreendem esse processo como a compra e venda de um produto, como uma relação empresa/cliente, ou seja, uma relação comercial, essa modalidade de ensino apresenta muitas falhas, comprometendo sua imagem e criando certa resistência no meio acadêmico.

Conforme reportagem de Mariana Tokarnia (2017), publicada pela Agencia Brasil em 28 de maio de 2017 durante o $10^{\circ}$ Congresso Brasileiro de Educação Superior Particular (Gramado/RS/Brasil), algumas dessas instituições que oferecem ensino a distância passam meses sem manter contato com os alunos. A reportagem teve acesso à pesquisa realizada pela Educa Insigths (2018), empresa especializada no desenvolvimento de soluções em pesquisa de marketing para o "mercado de Educação", como ela mesmo descreve em sua página eletrônica. A empresa fez uma pesquisa para saber como agem algumas instituições que 
ofertam EaD. Para isso, efetivou matrículas nessas instituições e verificou que ninguém comparecia às aulas e as atividades não eram realizadas. Conforme relato à reportagem da Agência Brasil, houve instituições que durante o ciclo da experiência ficaram mais de quatro meses sem manter nenhum contato. Esses dados reforçam a ideia de que alguns desses cursos à distância são, realmente, à distância de tudo, inclusive dos livros e do conhecimento, reforçando sua vocação mercadológica da educação.

Diante desses apontamentos, podemos afirmar que a lógica mercantil da Educação Superior impacta fortemente os processos formativos. Os elementos analisados evidenciam o caráter mercadológico da Educação Superior quando conduzida pelos ditames do mercado. A promessa de que uma educação de qualidade é medida por números e indicadores pode esconder inúmeras desigualdades. Conforme Abrams (2016), uma educação pautada pela ótica da iniciativa privada, necessariamente, não possui compromissos com aspectos fundamentais para a consolidação e bem estar das sociedades. Nesse sentido, características fundamentais do ensino público, como a inclusão e a responsabilidade social, ficam em segundo plano diante de programas padronizados para atingir um maior número de alunos a um menor custo. Somam-se a esses programas reformulações de currículos com vistas a aligeirar cursos, agrupar turmas sob disciplinas de núcleo comum para reduzir a jornada dos professores e utilizar amplamente a EaD.

Essas práticas condicionadas pelo mercado educacional induzem as IES a elaborarem seus currículos, principalmente, a partir de matrizes econômicas e tecnológicas, desapreciando conteúdos significativos para uma formação que seja crítica e racional. Para Nussbaum (2015, p.21), se esta tendência persistir, em breve serão produzidas pelo mundo inteiro gerações de "máquinas úteis, dóceis e tecnicamente qualificadas", em vez de cidadãos realizados, capazes de pensar por si próprios e de compreender o sentido do sofrimento e das realizações dos outros. Nussbaum $(2015$, p. 21) considera que as mudanças nos currículos, eliminando disciplinas das humanidades, implicam justamente na direção apontada de preparar um "conjunto de trabalhadores obedientes, tecnicamente treinados para executar os projetos das elites, que visam o investimento externo e o desenvolvimento tecnológico". Nesse sentido, toda política que represente um fomento à liberdade de pensamento dos alunos, constitui-se como uma ameaça.

Nessa perspectiva, Akkari (2011) estima que a educação contemporânea foi conquistada pelo discurso das empresas e modelos empresariais, adotando processos de avaliação e prestação de contas como quesitos de qualidade. Mais preocupante que isso é o fato destacado por Akkari (2011), de que os próprios formadores de professores se permitiram ser dominados pelos valores do neoliberalismo e do corporativismo. Dessa forma, aprender seria assimilar 
normas, objetivos, testes e, finalmente, simples números, sob um sistema de gerenciamento baseado nos ditames do mercado e não nas demandas sociais de uma determinada população.

Nesse sentido, adotar práticas de gerenciamento similares às adotadas por empresas eficientes está longe de resolver os problemas educacionais, em qualquer nível de ensino. Diferentemente de uma empresa, que tem o controle para executar e compor um quadro de colaboradores homogêneos, as instituições de ensino possuem um capital intelectual discente muito diversificado. As políticas de fomento e acesso ao ensino superior legitimam este quadro heterogêneo. Diante desse cenário, concordamos com Abrams (2016), que ao analisar a gestão de grupos educacionais privados dos Estados Unidos, concluiu que as regras de gerenciamento eficiente do mercado não são as mesmas da educação. Ao invés de aumentarem a qualidade da educação, podem legitimar diferenças gritantes. Isso, simplesmente, porque, como afirma Laval (2004), a escola não é uma empresa. Está muito longe disso. A finalidade da empresa é o lucro, diferentemente da finalidade educativa, que acima de tudo é a promoção da igualdade e do desenvolvimento social.

Por isso, um ensino superior guiado pelas regras do mercado tornase protagonista de dados como os apurados pelo presente estudo. Embora possam apresentar bons indicadores em avaliações de larga escala, como nas provas do ENADE, é fato que em muitas IES de propósito eminentemente privado/comercial/empresarial os processos formativos tornam-se aligeirados, apresentam pouco envolvimento com a pesquisa e, retomando Bittencour (2014), a relação pedagógica se converte em uma relação comercial, onde o processo de ensino se flexibiliza e se torna cada vez menos exigente intelectualmente.

\section{Considerações finais}

A avaliação da Educação Superior em uma época marcada pelo neoliberalismo pedagógico precisa observar alguns critérios fundamentais para o êxito dos processos formativos. Parece-nos claro que a determinação da qualidade da educação está intimamente ligada à formação dos professores e, essa, por sua vez, diretamente relacionada à necessária observação da prática pedagógica. Para Akkari (2011), seria ilusório analisar boas práticas de ensino sem observar os professores em ação. Desta forma, qualquer prática avaliativa que se traduz unicamente em meros números e indicadores pode não representar a verdadeira realidade no contexto do processo educativo. Quadros docentes com 
alta rotatividade e com regime de trabalho que não favorece o envolvimento com as IES podem se traduzir em critérios relevantes para avaliação da qualidade de educação oferecida.

Além disso, conforme previsto no Artigo 43 da LDB (BRASIL, 1996), a Educação Superior tem por finalidade "estimular o desenvolvimento do espírito científico e do pensamento reflexivo; [...] incentivar o trabalho de pesquisa e investigação científica, visando ao desenvolvimento da ciência e da tecnologia e da criação e difusão da cultura", objetivando, desse modo, "desenvolver o entendimento do homem e do meio em que vive". Como observamos nesta análise, ao não apresentarem compromisso com a realidade social em que estão inseridas e não possuírem envolvimento significativo com a pesquisa, muitas IES privadas não cumprem com o propósito estabelecido na LDB para a oferta do Ensino Superior de qualidade.

Os dados analisados neste estudo nos permitem constatar que a expansão da Educação Superior está mais associada ao crescimento de um mercado do que efetivamente à oferta de acesso a esse nível de educação. No setor privado, a disputa por alunos, o grande número de matrículas na modalidade à distância e o reduzido quadro de docentes, confirmam a máxima do mundo empresarial: "fazer mais com menos". Conforme constatado, as implicações formativas provenientes de modelos educacionais pautados pelo mercado vão além de números e indicadores que, supostamente, legitimariam a qualidade das instituições. Além disso, como verificamos, as condições de trabalho dos docentes e o envolvimento com pesquisa incidem diretamente sobre as características formativas dos discentes. Dessa forma, em uma proposta de Educação Superior pautada pela lógica do mercado, esses aspectos são secundários, desprezíveis, abrindo espaço para modelos educacionais padronizados e passíveis de replicação em larga escala.

Nesta perspectiva, concordamos com Bittencour (2014) no que tangencia a relação pedagógica entre professor e aluno, a qual passa a ser uma relação comercial, na qual o processo de ensino se flexibiliza e se torna cada vez menos exigente intelectualmente. Por fim, considerando (a) o discurso em prol da avaliação na Educação Superior como forma de garantir a qualidade por meio da competitividade; (b) a adoção da lógica do mercado como forma de melhor gerir as instituições em detrimento das condições de trabalho dos docentes, pesquisa e extensão; (c) o aligeiramento dos processos formativos, a despreocupação com a formação humana e com a responsabilidade social das instituições de ensino; e (d) o uso deturpado da educação à distância, fica evidente o caráter mercadológico que se oculta atrás de indicadores e de chavões de excelência em IES que sequer possuem sedes próprias, que tratam os discentes como clientes e que a finalidade primeira é a lucratividade e não a promoção do desenvolvimento humano das comunidades em que estão inseridas. 


\section{REFERÊNCIAS}

ABRAMS, Samuel E. Education and the Commercial Mindset. Cambridge, Massachusetts: Harvard University Press, 2016.

AKKARI, Abdeljalil. Internacionalização das politicas educacionais: transformações e desafios. Petrópolis, RJ: Vozes, 2011.

ALLEGRETTI, Fernanda. Escola de Fraudes: universidades manipularam resultados do Enade. Veja, 2016. Disponível em: https://veja.abril.com.br/educacao/escola-de-fraudesuniversidades-manipularam-resultados-do-enade/. Acesso em: 05 ago. 2018.

BATISTA, Michelle Espíndola. Avaliação da educação superior: qualidade e subjetividade. In: CUNHA, Célio da; SOUSA, José Vieira de; SILVA, Maria Abádia da (org.). Expansão e avaliação da educação superior: diferentes cenários e vozes. Belo Horizonte: Fino Traço, 2016. p. 113-132.

BALL. Stephen J. Diretrizes Políticas Globais e Relações Políticas Locais em Educação. Currículo sem Fronteiras, [s.l.], v. 1, n. 2, p. 99-116, jul./dez. 2001.

BALL. Stephen J. Sociologia das políticas educacionais e pesquisa crítico-social: uma revisão pessoal das políticas educacionais e da pesquisa em política educacional. Currículo sem Fronteiras, [s.l.], v. 6, n. 2, p. 10-32, jul./dez. 2006.

BERTOLIN, Júlio C. G. Avaliação da qualidade do sistema de educação superior brasileira em tempos de mercantilização: período 1994-2003. 2007. Tese (Doutorado em Educação) - Universidade Federal do Rio Grande do Sul, Porto Alegre, 2007.

BERTOLIN, Júlio C. G. Avaliação da educação superior brasileira: relevância, diversidade, equidade e eficácia do sistema em tempos de mercantilização. Avaliação, Campinas, v. 14, n. 2, p. 337-350, jul. 2009.

BITTENCOURT, Renato Nunes. A mercantilização educacional e a ideologia do ensino espetacular. Revista Lugar Comum, Rio de Janeiro, n, 43, p.249-264, 2014.

BRASIL. [Constituição (1988)]. Constituição da República Federativa do Brasil de 1988. Brasília, DF: Presidência da República, [1988]. Disponível em: http://www.planalto.gov. br/ccivil_03/constituicao/constituicao.htm. Acesso em: jun. 2020.

BRASIL. Ministério de Educação e Cultura. Lei número 9.394, 20 de dezembro de 1996. Estabelece as diretrizes e bases da Educação Nacional. Brasília, DF: MEC, 1996. Disponível em: http://www.planalto.gov.br/ccivil_03/leis/19394.htm. Acesso em: jun. 2020 .

BRASIL. Ministério de Educação e Cultura. Lei no 10.172, de 9 de janeiro de 2001. Aprova o Plano Nacional de Educação e dá outras providências. Brasília, DF: MEC, 2001. Disponível em: http://www.planalto.gov.br/ccivil_03/leis/leis_2001/110172.htm. Acesso em: jun. 2020. 
BRASIL. Ministério da Educação e Cultura. Instituto Nacional de Estudos e Pesquisas Educacionais Anísio Teixeira - INEP. Censo da Educação Superior 2018: notas estatísticas. Brasília, DF: INEP; MEC, 2019. Disponível em: http://download.inep. gov.br/educacao_superior/censo_superior/documentos/2019/censo_da_educacao_ superior_2018-notas_estatisticas.pdf. Acesso em: jun. 2020.

BURLAMAQUI, Marco Guilherme Bravo. Avaliação e qualidade na Educação Superior: tendências na literatura e algumas implicações para o sistema de avaliação brasileiro. Estudos em Avaliação Educacional, São Paulo, v. 19, n.39, p.133-153, jan./abr. 2008.

CASTELLS, Manuel. Um Estado destituído de poder? In: CUNHA, Célio da; SOUSA, José Vieira de; SILVA, Maria Abádia da (org.). Politicas públicas de educação na América Latina: lições aprendidas e desafios. Campinas: Autores Associados, 2011. p. 287-364.

CROSS, Di; THOMSON, Simon; SIBCLAIR, Alexandra. Research in Brazil: Areport for CAPES by Clarivate Analytics. Clarivate Analytics, 2018. Disponível em: http://www. capes.gov.br/images/stories/download/diversos/17012018-CAPES-InCitesReport-Final. pdf. Acesso em: 20 ago. 2018.

DARDOT, Pierre; LAVAL, Christian. A Nova Razão do Mundo: ensaio sobre a sociedade neoliberal. Tradução de Mariana Echalar. São Paulo: Boitempo, 2016.

EDUCA Insights. Sobre nós. Disponível em: https://educa-insights.com.br/. Acesso em: 24 ago. 2018.

GOMÉZ, Victor Manuel. Extansión y evaluación de la educación superior. In: CUNHA, Célio da; SOUSA, José Vieira de; SILVA, Maria Abádia da (org.). Políticas públicas de educação na América Latina: lições aprendidas e desafios. Campinas: Autores Associados, 2011. p. 165-192.

KOIKE, Beth. Kroton vira líder também na educação fundamental. Valor Econômico. São Paulo, abr. 2018. Disponível em: https://valor.globo.com/empresas/noticia/2018/04/24/ kroton-vira-lider-tambem-na-educacao-fundamental.ghtml. Acesso em 18 set. 2019.

LAVAL, Christian. A Escola não é uma Empresa: o neoliberalismo em ataque ao ensino público. Tradução de Maria Luiza M. de Carvalho e Silva. Londrina: Planta, 2004.

NUSSBAUM, Martha. Sem Fins Lucrativos: Por que a democracia precisa das humanidades. Tradução de Fernando Santos. São Paulo: Martins Fontes, 2015.

TELLO, César. Apresentação. In: TELLO, César (coord. e compilador). Epistemologías de la política educativa: posicionamentos, perspectivas y enfoques. Campinas: Mercado de Letras, 2013. p. 11-20.

TOKARNIA. Mariana. Educação superior à distância cresce em ritmo acelerado. Agência Brasil. Brasília, maio 2017. Disponível em: https://agenciabrasil.ebc.com.br/educacao/ noticia/2017-05/educacao-superior-distancia-cresce-em-ritmo-acelerado-mostra-censode-2015. Acesso em: 10 abr. 2020. 
FÁVERO, A. A.; CONSALTÉR, E.; TONIETO, C. A lógica do mercado e suas implicações...

VERHINE, Robert Evan; FREITAS, Antonio Alberto da Silva Monteiro. A avaliação da educação superior: modalidades e tendências no cenário internacional. Revista Ensino Superior, Campinas, v. 3, p. 16-39, 2012.

Texto recebido em $06 / 06 / 2020$.

Texto aprovado em $05 / 10 / 2020$. 